\title{
APRENDIZAGEM DO ENSINO: LIMITES \\ E POSSIBILIDADES
}

\section{L'APPRENTISSAGE DE L'ENSEIGNEMENT: LES \\ LIMITES ET LES POSSIBILITES.}

\author{
Joice Taise Martins
}

Larissa Gimenes de Araújo**

Resumo: O presente artigo trata do processo de ensino e de aprendizagem num momento de constituir-se professora por meio da prática pedagógica possibilitada via estágio supervisionado da $8^{\text {a }}$ fase do curso de Pedagogia na Universidade Federal de Santa Catarina. Apresentaremos primeiramente uma breve contextualização do trabalho realizado, posteriormente os conceitos necessários para entendermos que sujeitos são estes do processo de ensino e de aprendizagem, conceitos como: educação, ensino escola, criança e infância; em sequência, apresentaremos o trabalho desenvolvido para compreendermos os limites e as possibilidades que esta prática docente apresentou e sua relação com a própria aprendizagem no curso de Pedagogia. Os principais autores que nos guiam a pensar numa prática que seja humanizante e que contribua no desenvolvimento e aprendizagem das crianças são, fundamentalmente, Bernard Charlot (2000) e Suely de Amaral Mello (2006).

Palavra-chave: Estágio supervisionado. Prática pedagógica. Processo de 
ensino e de aprendizagem.

Résumé: Cet article traite du processus d'enseignement et d'apprentissage au moment de devenir une enseignante dans la pratique pédagogique. Cette pratique a été rendue possible par un stage supervisé à la $8{ }^{\text {ème }}$ étape du cours de Pédagogie à l'Université Fédérale de Santa Catarina. Tout d’abord nous présentons une contextualisation du travail réalisé, puis les concepts nécessaires pour comprendre quels sujets sont ceux du processus d'enseignement et d'apprentissage. Les concepts comme l'éducation, l'enseignement, l'école, l'enfant et l'enfance sont également évoqués. En conséquence, on présentera le travail pour comprendre les limites et les possibilités de cette pratique d'enseignement et sa relation avec le cours de Pédagogie. Les principaux auteurs qui nous ont servi de source pour une pratique humanisante et qui contribue au développement de l'apprentissage des enfants sont principalement Bernard Charlot (2000) et Suely de Amaral Mello (2006).

Mots-clés: Stage supervisé. Pratique pédagogique. Processus d’enseignement et d'apprentissage. 
No escrever o menino viu que era capaz de ser noviça, monge ou mendigo ao mesmo tempo.

O menino aprendeu a usar as palavras. Viu que podia fazer peraltagens com as palavras.

E começou a fazer peraltagens.

(O menino que carregava água na peneira - Manoel de Barros)

\section{Contextualização do estágio e conceitos fundamentais}

Antes de qualquer menção ao projeto e seu desenvolvimento, é necessário a contextualização do que foi realizado a partir da disciplina "Educação e Infância VIII: Exercício da Docência nos Anos Iniciais do Ensino Fundamental", que se encontra na grade curricular da $8^{\mathrm{a}}$ fase do curso de Pedagogia. Este estágio ocorre concomitante a outras disciplinas como "Organização dos Processos Coletivos do Trabalho Escolar", "Didática II: Processos de Ensino nos Anos Iniciais da Escolarização", "NADE - Narração de Histórias" e "Educação e Educação Especial: conceitos, concepções e sujeitos", e, portanto, faz-se necessário uma interlocução entre elas, pois este momento de entrada em campo é fundamental para a compreensão de teoria e prática, como também é momento único dentro do currículo de construção de conhecimento sobre a prática docente pautada nos conceitos e categorias apreendidas no decorrer do curso.

Para uma clara compreensão do desenvolvimento do projeto realizado, falaremos da inserção na escola, posteriormente na turma, a observação participante, como surge o planejamento e como 
este se desenrolou durante todo o "estágio supervisionado", em meio a isto, o diálogo com as disciplinas da $8^{a}$ fase.

Porém, antes de tudo, faz-se fundamental a explicação do percurso dentro do curso de Pedagogia, como também dos conceitos que nele foram sendo desenvolvidos e ampliados, pois estes marcaram e foram fundamentais para subsidiar este momento único de contato com as crianças do Ensino Fundamental I durante a formação que é o exercício da docência, do nosso fazer pedagógico enquanto acadêmicas.

Quando iniciamos o curso tínhamos uma percepção de educação, de ensino, de escola, de infância, mas à medida que nós adentrávamos nestas relações de construção de conceito e de conceber a prática docente foi-se então modificando, construindo, ampliando e se fortalecendo a partir de um referencial teórico que para cada uma de nós inicialmente era distante, mas que hoje está mais concreto e consolidado.

Desde o primeiro momento de entrada no curso nos foi questionado o que compreendíamos por infância, e logo nos veio à mente que é ser criança, mas também nos perguntavam que condição era esta? Apresentaram-nos a discussão acerca das Diretrizes Curriculares Gerais Nacionais que entraria em vigor no ano seguinte (2010), pois esta incluiria o ensino de nove anos do qual se inseriu crianças de seis anos nos bancos escolares, e questionava-se como retirar esta criança da Educação Infantil e colocá-la tão abruptamente no processo de escolarização? Que processo de ensino iria se constituir? Que educação seria essa? Pois pensar num modelo de ensino tem por base qual educação queremos e a partir delas como se dará o processo de escolarização.

Questionaram-nos: qual escola que temos? Como ela foi se constituindo, em que moldes e qual a sua finalidade formativa? 
E como esta compreende seu sujeito? Como se construiu esta instituição? Quais as concepções de escola e modelos de formação a constitui? Portanto, em meio a estas questões, no decorrer do curso, conceitos como Educação, Ensino, Escola, Criança e Infância foram sendo apresentados para nos mostrar que diante de cada perspectiva teórica há uma compreensão de acordo com a visão de mundo e de sujeito que existe. Sendo assim, faz-se importante apresentar a perspectiva de cada conceito que concebemos.

Primeiramente, é importante destacarmos a diferença entre educação e ensino, ambos possuem dimensões diferenciadas, mas que se englobam. O primeiro termo se refere ao desenvolvimento do sujeito em sua omnilateralidade e não está diretamente relacionada à instituição escolar. Engloba também os processos de ensino e de aprendizagem, que segundo Vygotsky ${ }^{1}$

[...] todo aprendizado é necessariamente mediado [...] o primeiro contato da criança com novas atividades, habilidades ou informações deve ter a participação de um adulto. [...] o ensino deve se antecipar ao que o aluno ainda não sabe nem é capaz de aprender sozinho, porque, na relação entre aprendizado e desenvolvimento, o primeiro vem antes.

Portanto, o processo de ensinar e aprender se constituem mutuamente, à medida que eu ensino também aprendo e vice-versa, ou como diria Paulo Freire: "Ninguém educa ninguém, ninguém se educa a si mesmo, os homens se educam entre si, mediatizados pelo mundo." Devido a este processo, há a transmissão e perpetuação dos grupos humanos. Entendemos, assim, que o que é transmitido nesta relação de gerações mais velhas para as mais novas são os valores, regras sociais, linguagem, conhecimentos, técnicas, hábitos, enfim, a cultura de um grupo (DUARTE, 2011). 
Já o ensino é algo que se insere dentro do campo mais amplo chamado Educação, entretanto pressupõe a intencionalidade, e logo que se pergunta o que se ensina, devemos saber a quem se ensina e por isso nos remetemos aos termos ensino e aprendizagem, termos estes indissociáveis. Partimos do pressuposto que para que este processo se efetive as relações sociais são fundamentais, pois elas são mediadoras das funções psicológicas superiores. O ser professor se traduz em sujeitos que possuem um nível maior de abstração dos signos e instrumentos desenvolvidos pelo ser humano ao longo do tempo, como é o caso da linguagem escrita. Por isso, na escola os professores são fundamentais na mediação destes instrumentos e signos para o processo de ensinar, buscando, assim, as aproximações de conhecimento sobre o mundo natural e sobre a cultura, do qual Vygotsky denomina de Zona de Desenvolvimento Proximal (ZDP), trazida pelas crianças para a efetivação da aprendizagem. De acordo com Bianca et al. ([20--], p. 1):

A zona de desenvolvimento proximal caracteriza a distância entre o nível de desenvolvimento real e o nível de desenvolvimento potencial determinado pela solução de problemas sob a orientação ou ajuda de um adulto ou crianças mais capazes. O importante para Vygotsky é, além do que se faz sozinho, o que se faz com a ajuda dos outros. Dessa forma, a aprendizagem desperta ${ }^{2}$ processos internos de desenvolvimento que só podem ocorrer quando o indivíduo interage com outras pessoas.

Quanto à escola, esta tem assumido um papel social de manutenção do sistema para qual serve, papel este que foi se constituindo e reafirmando ao longo do tempo desde sua elaboração. Não obstante, a escola também é espaço de resistências na medida em que é espaço de formação humana e de transmissão de conhecimentos 
historicamente acumulados. É espaço de socialização, de transmissão de valores e conhecimentos e por ser uma instituição complexa em que há um conjunto de forças, tais como as Diretrizes Curriculares Nacionais (DCN), que trazem uma concepção de formação, construção de escola, e por outro lado o próprio corpo escolar e os professores também com sua concepção de mundo atuam seja na resistência, seja ainda na própria reprodução. Ainda em relação à escola, podemos dizer que esta se constitui como uma instituição social complexa imersa nas relações existente nesta sociedade e, portanto,

[...] a escola não é uma ilha na sociedade. Não está totalmente determinada por ela, mas não está totalmente livre dela. Entender os limites existentes para a organização do trabalho pedagógico ajuda-nos a lutar contra eles; desconsiderá-los conduz a ingenuidade e ao romantismo. (SCHREIBER; GARCIA, 2012, p. 2).

De acordo com Sarmento e Pinto (1997), a escola ao longo do tempo foi se caracterizando por ser espaço privilegiado da infância, espaço primeiro de preparar as crianças para a "idade adulta" e para o trabalho e posteriormente de acolhimento das novas gerações e de sua mediação da cultura. Contudo, tendo em vista a forma de socialização de que compartilhamos, devemo-nos questionar como as crianças vêm sendo inseridas neste espaço. Devemos pensar para qual sociedade estão sendo formadas as crianças, revendo o papel social da escola em nossa sociedade, inclusive nos cursos de formação de professores. Para tanto, precisamos nos questionar como a escola de hoje vê a criança, qual sua concepção de criança, infância, escola.

Ao longo do nosso curso nos desafiamos a entender mais e melhor o sujeito criança e suas especificidades para, a partir daí, 
pensar qual escola queremos construir e que tipo de professoras queremos nos formar.

Partimos do entendimento, o qual foi sendo construído ao longo do curso, de que a criança é um ser humano de pouco idade, em desenvolvimento, e não um adulto em miniatura, como era antes compreendido, que deve ser protegida, participar ativamente nas decisões que lhe diz respeito e receber aquilo que lhe é fundamental para sua existência e desenvolvimento. Já a infância é a condição social de ser criança, universal e múltipla, apresentada no decorrer do curso no conjunto das disciplinas que é eixo curricular - Educação e Infância I a VIII.

A infância é uma categoria social que foi se constituindo da invisibilidade para a visibilidade, ou seja, partiu da não distinção do adulto para considerar as especificidades e particularidades da criança. A visibilidade que é dada à infância não elimina as ambiguidades existentes com relação a essa temática e a prevalência das expectativas dos adultos sobre as crianças. A sociedade busca cada vez mais uma elaboração do conhecimento sobre a infância e há uma crescente especialização do campo do conhecimento.

Uma abertura do campo investigativo começou a considerar a infância enquanto fenômeno social, sendo uma categoria autônoma a ser analisada nas suas relações com a estrutura social. Este tipo de análise permitiu identificar as contradições que envolvem a categoria social da infância e que podem ser observados por intermédio dos ineficazes planos políticos de diversos países (SARMENTO; PINTO, 1997).

A contradição mais latente diz respeito em apostarmos nas crianças como o futuro da nação e ao mesmo tempo permitir que elas sejam submetidas à constante opressão. Não raramente ob- 
servamos situações paradoxais da infância sendo representadas nos mais diversos espaços sociais.

No campo pedagógico, o aporte teórico sobre a infância ainda está em elaboração e a pedagogia da infância tenta articular o campo prático e científico a fim de construir uma prática. Precisamos pensar na infância não somente enquanto tempo cronológico, mas também enquanto tempo de direitos.

A estruturação do cotidiano pedagógico deve levar em conta o lugar social das crianças e suas famílias, sendo que o espaço das instituições, escolares ou não, e a organização das atividades devem ser pensados para as crianças viverem sua infância em sua plenitude de direitos. Se as crianças, muitas vezes, passam a maior parte do tempo na escola e, por vezes, sem possibilidades de outras vivências, devemos, portanto, utilizar este espaço para as aprendizagens, viabilizar por meio do ensino o acesso ao conhecimento, possibilitar que se desenvolvam em suas multiplicidades e características próprias humanas, em suas múltiplas linguagens. Pois se o maior tempo que passam é na escola, esta deve ser, portanto, a mediadora do conhecimento.

Para caminhar pelas trilhas da infância é preciso compreendê-la enquanto experiência que não se repete e não é possível de nomear, pois essa imagem dinâmica não se deixa capturar e categorizar. Podemos então afirmar que não temos conhecimento das condições de vida das crianças e que vamos conhecendo-as aos poucos conforme a interação e a necessidade de conhecer este sujeito que é a criança.

Nem sempre a criança foi pensada na perspectiva dos direitos e muitas vezes as políticas públicas que dizem proteger os direitos das crianças são direcionadas para a "falta", ou seja, para aquilo que se acredita que a criança não tem. Dessa forma, a atuação pro- 
fissional dos educadores, especialmente aqueles que têm como foco as crianças, é inundada de responsabilidades para além das educacionais. Passa a ser função do professor "resolver" questões familiares, econômicas, sociais, entre muitas outras.

E mesmo que tenhamos em vista que estas questões não são propriamente preocupações do professor, elas passam a ser responsabilidade não somente deste profissional, mas também da escola, tendo em vista a educação ser um direito da criança e esta um sujeito em desenvolvimento que deve ter seus direitos garantidos. Por ser relações que estão postas nesta sociedade, torna-se inevitável ao professor abordar questões que ultrapassam os conteúdos escolares.

Diante do exposto, ainda que esta seja uma reflexão breve e resumida, foi a partir desse referencial oferecido durante a formação no curso de Pedagogia que chegamos à escola, nos encontramos com as crianças e pensamos nosso "estágio supervisionado". É a partir disso que concebemos fundamental a relação com a criança e o respeito a seus direitos mais fundamentais.

\section{Inserção na escola e sujeitos da interação}

Chegamos à Escola Estadual Padre Anchieta com expectativas de toda ordem porque tentamos imaginar as situações e vivências que nós, juntamente com as crianças, iríamos experienciar. Contudo, esquecemos que no cotidiano escolar há muito mais vida do que a nossa imaginação pode criar.

Este fato nos ajuda a buscar um lugar na vida das pessoas que vai se constituindo para além do mero expectador que sonha horas antes com o desenrolar do espetáculo. O lugar a ser ocupado por nós é de quem observa a realidade, mas também participa na 
construção dela. De quem registra e ao mesmo tempo tenta contribuir na intervenção junto às crianças. Que constrói significados a partir daquilo que as próprias crianças nos indicam.

Em continuidade à formação, nos é possibilitado por meio do "estágio obrigatório" a aproximação com o contexto escolar, com os sujeitos que nele estão inseridos e com a prática pedagógica nos anos iniciais.

Iniciamos esta etapa acadêmica com a escolha da Escola Estadual Padre Anchieta, localizada no bairro Agronômica, como campo de estágio. Mas, para a inserção neste espaço e falar de tal lugar, é necessário sua contextualização e dos sujeitos nela inserido.

A escola atende principalmente crianças e adolescentes que vivem nas comunidades do Maciço ${ }^{3}$ do Morro da Cruz. Conta com 63 professores em toda a escola, sendo que nove atuam nos anos iniciais e a maioria destes são contratados na modalidade Admitido por Caráter Temporário (ACT). A escola conta também com diversos projetos oferecidos pelo Ministério de Educação e Cultura (MEC) como o projeto "Olhar Brasil", projetos oferecido pelas universidades tanto a federal quanto a estadual e projetos de Organizações Não Governamentais (ONGs). O tema do projeto da escola para este ano é "Ler e aprender para libertar" e, portanto, nossa ação como estagiárias perpassa este foco.

Nossa entrada na escola foi possível principalmente devido ao projeto da escola, pois a questão da dificuldade de leitura e da escrita é fator latente na aprendizagem das crianças e da ação dos professores. Portanto, nós, como estagiárias, tivemos o foco de observação e elaboração do planejamento pautado nesta temática. Durante o período de observação, participamos de momentos de sala de aula com as crianças, conselho de classe, conversas com o professor responsável de turma, direção da escola etc. 
Dentre as quatro opções de turma a serem escolhidas, ficamos com o $4^{\circ}$ ano que conta com 18 crianças com idades entre nove e 14 anos. De acordo com a temática da escola com relação à leitura, percebemos que havia crianças que já dominam a leitura e a escrita, compreendendo inclusive sua função social, e crianças que ainda não codificam e decodificam as palavras. De modo geral, podemos afirmar, ainda que nossas observações tenham sido breves, que a maior dificuldade do grupo é com a leitura.

Este fato pode ser justificado por intermédio dos relatos realizados pela professora de sala. Em um desses relatos ela explicitou sua preocupação quando as crianças copiaram um texto que ao final dava instruções para se deslocarem até o final da sala e todos permaneceram sentados. Este episódio deixa claro que a leitura e a escrita não estão sendo apreendidas de forma a tornar as crianças ativas, críticas e participantes do processo de ensino e de aprendizagem. Além da questão da leitura e escrita, outras situações nos chamaram a atenção e vamos descrever um pouco a seguir.

Apontamos a oralidade das crianças como um aspecto importante a ser observado, que se dá em dois momentos distintos: quando se expressam livremente na sala, com a professora e entre pares, o que por vezes se dá em tom bastante alto; quando são solicitadas a realizar leitura em "voz alta", momento em que o tom da voz é muito baixo.

A participação das crianças no grupo é muito interessante, sendo o momento em que expressam o desejo de aprender, o apreço pelos colegas e pela professora, além de contribuírem com situações de seus cotidianos. Contudo, observamos que a participação da criança, enquanto direito fundamental, é por vezes negligenciado.

De acordo com Sarmento e Pinto (1997), dos direitos enunciados pela Convenção sobre os Direitos da Criança, da Organização 
das Nações Unidas (ONU), o que mais sofre resistências quanto a sua aplicação é o direito da participação. Tendo em mente a perspectiva das crianças como produtoras de cultura, pensamos que tanto as propostas pedagógicas, quanto as relações estabelecidas na escola, assim como o próprio espaço da instituição, devem ser pensados para que as crianças vivam sua infância em sua plenitude de direitos. Deixar as crianças opinarem sobre como seus espaços devem ser construídos e organizados ou, ainda, como práticas devam ser conduzidas e, ainda, respeitar suas opiniões, são desafios a serem enfrentados por muitos de nós.

Ainda destacamos as relações afetivas estabelecidas na sala de aula, especialmente entre crianças e professora. É evidente o quanto as relações de afeto contribuem para valorar o cotidiano escolar, os laços de amizade, a questão da autoestima das crianças, o cuidado ao lidar com o outro de modo respeitoso também contribui para o processo de aprendizagem.

Dentre várias situações que nos chamaram a atenção e que não deixam de ser importantes, apresentamos estas em destaques e não outras, pois estas escolhas são necessárias e decorrentes do nosso entendimento do que se faz necessário para o ensino e a aprendizagem das crianças. Ressaltamos que, quanto mais o educador conhece as crianças, seus contextos e histórias de vida, seus gostos e desejos; ou melhor, quanto mais o educador observa, registra e reflete sobre sua ação e das crianças, mais qualificadas serão suas escolhas e opções teórico-metodológicas para o processo de ensino e de aprendizagem.

No decorrer desses dias de observações podemos sinalizar algumas questões, problemas que serão enfrentados no exercício docente. Como pensar o planejamento pedagógico para as crianças que ainda não estão alfabetizadas? E aquelas que têm algum 
tipo de deficiência? Que métodos ou quais estratégias poderão ser utilizados nestes casos? Como se procederá nossa prática em uma heterogeneidade vasta e diante das especificidades de cada criança? Como fazer para que nosso fazer pedagógico atinja todas as crianças de modo a respeitá-las em seus anseios?

Acreditamos que nossas ações estiveram pautadas na máxima aproximação, apropriação e compreensão do conhecimento. Por isso, nosso exercício constante é pensar nas mais possíveis estratégias de aprendizagem para que nossa ação vá ao encontro dos direitos das crianças à proteção, à provisão e à participação.

Para isso, buscamos construir um diário de cada criança onde colocariam o registro de uma parte da vivência delas em sala/escola e a vivência fora da escola para que assim pudessem escrever para si mesmas como uma recordação de suas experiências de vida. Planejamos iniciar a aula com a leitura de um livro e ao final da aula uma criança pudesse ler uma história.

Também procuramos dar continuidade ao trabalho pedagógico com atividades que possibilitassem explicar o conteúdo e posteriormente escrever para que não se torne uma simples cópia; buscar o conhecimento prévio das crianças acerca dos assuntos considerando suas colocações.

\section{O planejamento "compartilhado com a escola": limites e possibilidades}

A educação é direito das crianças e desse modo o fazer pedagógico deve buscar um trabalho que contemple esse direito de forma intencional e com qualidade e, se intencional, é trabalho pedagó- 
gico preocupado com o planejamento.

Muito mais que uma descrição de atividades que lista passo a passo o que vai ser realizado, o planejamento é um documento reflexivo que tem origem na própria prática pedagógica. $\mathrm{O}$ ato de planejar traça um roteiro que indica a direção dos objetivos, e estes dizem respeito ao conhecimento. Planejar não significa engavetar uma prática, mas pensá-la de forma flexível, de uma maneira que seja possível retomá-la e repensá-la: “[...] as atividades de um planejamento burocratizam-se quando o educador dicotomiza o conteúdo da matéria do conteúdo do sujeito e da dinâmica do grupo; ocasionando assim a perda do significado." (FREIRE, 1997, p. 55).

O planejamento deve caracterizar-se principalmente pela intencionalidade do processo educativo. Pois, mesmo quando não exprimem uma intencionalidade assumida, deixam revelar as concepções principalmente, neste caso, de criança, infância e processo de ensino-aprendizagem. Mas se não é a forma que define o que é um planejamento, qual é o elemento definidor? Devemos pensar então em quais são os princípios que amparam sua organização, quais as concepções. Do conjunto de saberes e conhecimentos socialmente construídos e historicamente acumulados, quais eu escolho para compor meu planejamento?

Segundo Freire (1997), o planejamento constrói-se a partir da avaliação e, certamente, em olhar as próprias crianças, seus movimentos, gestos, gostos e conhecimentos sobre o mundo. É processo de observação, reflexão, formulação de hipóteses, planejamento, observação... e assim ciclicamente.

A proposta de trabalho com as crianças deve ampliar o repertório cultural delas, por isso o movimento acima descrito é tão fundamental. Se não conhecemos as crianças, se nada sabemos sobre 
elas, como podemos propor alguma coisa significativa? Isto não significa "mapear" sua realidade sem ampliar seus conhecimentos, ou, ainda, saber os conhecimentos prévios e seus interesses não é simplesmente acatar o que elas trazem para a escola, mas sim levar em conta esses conhecimentos na nossa proposta como partida da ampliação dos repertórios.

Conhecer as crianças e suas realidades não pode virar apenas pretexto para listar tarefas a serem preenchidas ao longo do dia. Temos de ter em mente seus direitos e, assim, o planejamento vai se desdobrando no dia a dia com as crianças em práticas que são muito mais significativas do que a mera aquisição mecânica dos conteúdos das áreas de conhecimento e a quantificação de atividades.

O planejamento no cotidiano escolar é ferramenta para auxiliar na proposta de momentos significativos na vida das crianças, que levem em conta as relações, os conhecimentos das áreas de saber, as diversas linguagens e a brincadeira como elemento primordial, pois, como havíamos colocado anteriormente, a escola é o espaço em que as crianças passam grande parte do seu tempo, compreendendo que este é um espaço de transmissão do conhecimento acumulado e das práticas culturais.

\section{Primeiro Planejamento e o (re)planejamento: formação de leitores e escritores}

Partimos do objetivo de propiciar a alfabetização com Letramento a partir das práticas de leitura, escrita e interpretação de acordo com o projeto proposto pela Escola de Educação Básica 
Padre Anchieta. Para tanto, criar situações de ensino para que cada criança possa:

- Compreender a função social da escrita;

- aprimorar os conhecimentos de leitura e escrita;

- ampliar o vocabulário;

- vivenciar uma relação de fruição da leitura;

- reconhecer-se como sujeito do que realiza e, desse modo, construir sua identidade.

Partimos também do pressuposto que o ensino da leitura e da escrita não pode se resumir em treinamento de técnicas, exercícios de prontidão, codificação e decodificação. Ao contrário, cada vez mais há em nós, pedagogas em formação, a convicção de que a escrita deve ser apresentada como instrumento cultural complexo, produto da cultura e com função social. Desse modo, é imprescindível apresentar a função social da escrita, criando na criança a necessidade de apreender este instrumento cultural.

Para tanto, Mello (2006) nos mostra o quanto que se faz necessário a inserção de atividades, como pintura, desenho, oralidade, modelagem, brincadeiras etc., as quais impulsionam a apropriação da leitura e da escrita. E a inserção da criança na atividade se dá à medida que o educador(a) cria situações de ensino para que as crianças sintam a necessidade de busca daquele conhecimento. A criança é sujeito do processo de conhecimento, ou seja, é sujeito quando participa ativa e intelectualmente da atividade que está realizando, tornando-a, assim, significativa.

A escrita deve tornar-se para a criança instrumento de expressão, fruição, memória, aprendizado, e ser utilizado em atividades que envolvam a sua função social. Portanto, para que nossas ativi- 
dades fossem significativas e se apresentassem como um projeto, definimos como eixo norteador do trabalho pedagógico o livro $O$ menino marrom, de Ziraldo. Partindo dele, os diários foram elaborados pelas crianças. Juntamente com o livro-eixo do planejamento, foram apresentados outros gêneros textuais, como poemas e crônicas.

A inserção deste livro, além de ser eixo da nossa prática, teve aspectos importantes que foram destacados na semana da consciência negra (20/11), proposta pedagógica que se realizou durante uma semana em todas as turmas da escola.

Como partida da ação docente, iniciamos com o livro A caligrafia de Dona Sofia, de André Neves, pois este trouxe elementos importantes de discussão sobre: como a memória é reavivada pela escrita; a importância de escrever e de ler por fruição; a compreensão do que se escreve, enfim, elementos cruciais para o projeto da escola, como também para o foco da nossa prática pedagógica. Tal prática, possibilitada por meio do estágio, além destas questões que o livro aborda, nos possibilitou a proposta da construção dos diários de cada criança, que tiveram a possibilidade de serem autoras, produtoras de texto.

Tendo a compreensão de como foi pensado o projeto que seria desenvolvido em conjunto com as crianças, e sabendo também que, por mais que tenhamos um planejamento pronto, ele não está acabado e é somente ponto de partida para nossa ação docente. $\mathrm{O}$ planejamento é uma base, mas que no seu desenrolar será modificado, pois ele não é fixo, fechado e imutável, mas, à medida que é posto em prática, há a necessidade de reavaliação e reformulação.

Nosso planejamento, por mais que se modificou, manteve a proposição de atividades com os livros, as músicas, os jogos, as 
brincadeiras, as pinturas, pois estes estavam intimamente ligados ao nosso objetivo, que era apresentar a escrita na sua função social e possibilitar uma aproximação do gosto pela leitura às crianças, como também possibilitá-las o acesso aos conhecimentos produzidos historicamente, com a cultura e o desenvolvimento das múltiplas linguagens. Para este nosso momento de leitura para as crianças e fazendo uso das palavras de Walter Benjamim, em uma correlação do artesão com o contador de histórias, é que

[...] os movimentos precisos do artesão, que respeita a matéria que transforma, tem uma relação profunda com a atividade narradora: já que esta também é, de certo modo, uma maneira de dar forma à imensa matéria narrável, participando assim da ligação secular entre mão e voz, gesto e a palavra. (BENJAMIN, 1994, p. 11).

E mais, esta nossa prática de leitura em sala se faz fundamental, pois

[...] o estímulo à leitura pode se dar a partir do contato com histórias, desde a mais tenra idade, quando a criança encontra nelas uma maneira de viajar em aventuras fantásticas e viver em outro mundo, encontrando o prazer e associando-o aos livros. (CACCIOLARI, 2009, p. 8).

Logo que foi posto em prática o planejamento no primeiro dia da docência houve a necessidade de reformulação. Isto porque fomos observando os movimentos das crianças, avaliando os objetivos e os resultados, e a partir da reflexão sobre nossa prática foram surgindo apontamentos que tinham a ver com a necessidade de replanejamento.

A realidade dos replanejamentos só é possível a partir de um 
posicionamento teórico-metodológico que tem por pressupostos dois principais pontos: o primeiro diz respeito ao entendimento de que a criança é sujeito no processo de ensino e que, portanto, deve ser percebida neste processo a fim de que ela possa indicar os possíveis encaminhamentos e/ou desdobramentos do projeto; o segundo se refere ao entendimento de que o planejamento é um guia, fio condutor da prática, não um documento engessado, e está intimamente ligado às necessidades advindas da realidade.

A necessidade de replanejar se deu porque o plano inicial foi pautado em ações que de certo modo são abstratas. Por mais que tenhamos pensado em crianças reais e suas reais necessidades, era algo ideal, mas que na prática há outro movimento. Mudamos a organização das atividades, dos tempos, dos encaminhamentos, mas, como já havíamos dito, mantivemos o seu conteúdo, pois era base do projeto, os livros, os jogos e as brincadeiras, tudo estava articulado com o conteúdo do livro $O$ menino marrom.

A cada aula terminada, ao olhar para o planejamento, existia ao menos dois encaminhamentos que necessitavam de mudanças, mas que por termos um direcionamento do que queríamos fazer, de objetivos a serem alcançados e um eixo de trabalho, o planejamento pôde ser tranquilamente reformulado a partir das necessidades advindas das necessidades reais das crianças.

\section{A realização do exercício docente}

Ler e Escrever para voar, viajar e libertar! O diário como meio formativo 
Diante dos objetivos expostos no planejamento e avaliando aquilo que foi sendo realizado juntamente com as crianças, podemos afirmar que diversas situações significativas foram sendo desenhadas, tanto para as crianças quanto para nós pedagogas em formação.

Tínhamos como preocupação central a ampliação dos repertórios de leitura e escrita e contribuir para a maior participação das crianças, especialmente no que diz respeito à oralidade. Para isto, tentamos organizar as atividades num ritmo que buscasse a participação de todos, sendo que por vezes estendíamos o tempo de determinadas atividades para que elas fossem de fato significativas e não acabassem sendo interrompidas no seu decorrer com o intuito apenas de quantificá-las.

Com relação à oralidade, as rotinas de rodas de conversa que se constituíam em momentos em que as crianças falavam sobre suas experiências dentro e fora da escola, oportunizaram o estabelecimento de uma relação afetiva e cordial entre estagiárias, professora de sala e crianças. Além disso, as crianças foram a cada encontro expressando cada vez mais suas experiências para o grupo, num exercício de escuta do outro, de respeito e de aprendizagem. Algumas das crianças que sentiam mais dificuldade em se colocar para o grupo com o tempo foram demonstrando pequenos gestos na direção de uma participação.

Já com relação à ampliação dos repertórios literários, esta ficou visível nos momentos em que as crianças faziam as relações entre o cotidiano escolar e os aspectos explorados na literatura. Um bom exemplo disto é a crônica Defenestração, de Luis Fernando Verissimo, em que as crianças usavam com humor a palavra conhecida por meio da leitura. A ampliação do repertório literário 
das crianças foi basicamente proporcionada através da leitura e/ ou contação de histórias por parte das estagiárias, as quais utilizaram diversas literaturas conforme planejamento final. Nestes momentos primamos por haver um número significativo de livros que pudessem circular entre as crianças e estas, por sua vez, pudessem manusear e conhecer as produções literárias, assim como disponibilizar tempo necessário para ler, folhear, brincar e interagir com o livro ou ler para um colega.

Ao trazermos esse contato com os livros, com a leitura e a contação foi fundamental para o repertório cultural das crianças, como também modos de ler, de contar. Cada interação com a produção humana (repertório cultural), por intermédio da relação educativa, acaba por favorecer a ampliação da imaginação.

A imaginação é uma função vital do cérebro humano. Vygotsky mostra esta afirmação quando estabelece quatro formas básicas de ligação da atividade criadora do cérebro humano com a realidade. A primeira é a de que a fantasia é construída com elementos da realidade. A imaginação se apoia na experiência. A atividade criadora da imaginação se encontra em relação direta com a riqueza e a variedade da experiência acumulada pelo homem, porque esta experiência. É o material com que a fantasia erige os seus edifícios. Quanto mais rica seja a experiência humana, tanto maior será o material de que dispõe essa imaginação. Por isso a imaginação da criança é mais pobre que a imaginação do adulto, por ser menor a sua experiência. (HONORATO, [20--], p. 2).

A escrita que foi sendo desenvolvida pelas crianças durante o nosso projeto de ensino foi aos poucos ganhando cada vez mais sentido à medida que as próprias crianças iam se exercitando enquanto produtoras de texto. Como exemplo, temos o texto co- 
letivo escrito para finalizar a produção do diário que teve maior participação efetiva das crianças do que no primeiro texto coletivo realizado. Isto porque, ao final desse projeto de ensino, elas começam a ver com mais clareza os objetivos de cada encontro e que eles tinham início, meio e fim, como também tinham ampliado o conhecimento sobre a própria estrutura textual e os elementos que a constituem.

Refletindo sobre a prática da leitura, podemos considerar que foram poucos os momentos em que as crianças realizaram atividades dirigidas de leitura individual ou em pequenos grupos, ou seja, foram poucos momentos em que elas realizam uma leitura com fim em si mesma. As atividades estavam voltadas para leitura de pequenos trechos, interpretação e produção de texto. Contudo, podemos inferir que podemos mostrar que saber ler com autonomia e proficiência é importante e, além disso, é prazeroso.

As situações significativas só podem ter este caráter se a criança estiver engajada conscientemente na atividade, sabendo o que está fazendo e seus objetivos: “[...] enfim, quanto maior a presença intelectual da criança na escola, maior a possibilidade de que a tarefa proposta se configure como uma atividade significativa para a criança." (MELLO, 2006, p. 185).

Durante o exercício docente fornecemos às crianças mais do que leitura e escrita: a elas foram possibilitadas relações com outros conhecimentos e linguagens. Possibilitamos o conhecimento de palavras novas ao realizarmos atividades utilizando o dicionário. Atividades envolvendo áreas do conhecimento específicas como a Física, por exemplo, quando trabalhamos os conhecimentos necessários para entender os princípios do Disco de Newton, além da estética das cores. Contribuímos para que as crianças compre- 
endessem a importância do planejamento na realização de suas próprias atividades, podendo este aspecto ser melhor observado nos momentos de produção da capa do diário e de confecção de um brinquedo, que foi o pião.

Estas relações e aprendizagens a "mais" demonstram que em uma ação pedagógica há marcas de intencionalidade mediante o planejado para cada ação, mas que há também o que denominamos de currículo oculto, que tanto se apresenta pelos conteúdos que serão abordados pela escolha do professor, ou pelo que já está posto no livro didático, quanto também pelas ações, gestos, colocações e ideias que por vezes não temos consciência total destas, mas que também são formadoras:

O currículo oculto é constituído por todos aqueles aspectos do ambiente escolar que, sem fazer parte do currículo oficial, explícito, contribuem, de forma implícita para aprendizagens sociais relevantes $[. .$.$] o que se aprende no$ currículo oculto são fundamentalmente atitudes, comportamentos, valores e orientações... (SILVA, 1999, p. 78).

Portanto, ao saber qual entendimento temos de sujeito e sociedade, nossas práticas também estarão voltadas neste sentido, sendo expressas conscientemente ou não, contudo, sempre formadoras.

\section{Considerações finais}

Nossa aprendizagem do ensino teve muitos significados que dizem respeito até mesmo com a identificação com o curso de Pedagogia e com a profissão de professora. Isto porque iniciamos 
o estágio com muitas dúvidas e nenhuma experiência com docência, o que nos levou a duvidar se éramos capazes de estar com as crianças em situações de ensino. Esta dúvida só pode ser desfeita no encontro com as crianças e na relação com elas. E só pôde se tornar concreto este olhar para nós mesmas enquanto professoras quando as crianças nos viram como tais. Este pensamento vem ao encontro de que:

A humanidade (no sentido de 'ser humano'), em oposição à animalidade (o 'ser animal') não é um dado presente por natureza em cada individuo isolado, é o mundo social humano; e cada indivíduo natural torna-se humano ao 'hominizar-se' através de seu processo de vida real no âmago das relações sociais [...] a educação é a apropriação, sempre parcial, de uma essência excêntrica do homem. (CHARLOT, 2000, p. 52).

Afirmamos isto porque é na relação com as crianças e na prática pedagógica que vamos-nos constituindo como docentes, como sujeitos professores, e ao mesmo tempo sempre nesta apropriação parcial que é aprender a ser professora, pois as escolas serão diferentes, os contextos serão outros, as crianças serão outras, a organização da escola será outra, assim como nós mesmas seremos outras. Como diria o pensador grego Heráclito de Efeso: "Ninguém entra em um mesmo rio a segunda vez, pois quando isso acontece já não se é o mesmo, assim como as águas que já serão outras” e, portanto, estamos sempre nos tornando professoras.

Dessa forma, foi estando na escola, na relação com as crianças, que fomos aos poucos nos posicionando enquanto professoras-estagiárias capazes de proporcionar atividades significativas para as crianças.

No movimento de proporcionar momentos importantes para 
as crianças foram criados em nós momentos significativos, de aprendizagem da docência. Tínhamos em nós o móbil principal de estar com as crianças e estabelecer uma relação significativa com elas, e partir desse móbil outros foram estabelecidos que fizeram com que este estágio se tornasse um momento de encontro.

Este nosso móbil nos motivava, porque, além de momento único na nossa vida acadêmica, era também um encontro com nós mesmas, na medida em que era a busca de uma identidade como sujeitos professoras e esta forma de estar no mundo vistas como docentes, por isso entendemos que o estágio vem na compreensão de que “[...] significar é sempre significar algo a respeito do mundo, para alguém ou com alguém [...] o sentido é produzido por estabelecimento de relação, dentro do sistema, ou nas relações com o mundo e com os outros." (CHARLOT, 2000, p. 56).

A partir da motivação de estar com as crianças, tínhamos o objetivo de estabelecer um vínculo com as elas, estabelecer uma relação afetiva, de aprender a relação professora-crianças, condições que consideramos importantes dentro do ensino e de aprendizagem.

Durante o desenrolar do planejamento pudemos perceber estes objetivos sendo alcançados na medida em que foi estabelecido o vínculo com as crianças e que passamos a nos relacionar afetivamente com elas, culminando no último dia de estágio em que manifestaram desejo de não irmos embora. Nosso aprendizado foi perceber as possibilidades da relação entre a criança e a professora, da importância primordial do respeito nessa relação, e que é possível uma relação afetuosa em um ambiente escolar.

Movemos-nos no sentido de colocar em prática aquilo que havíamos sonhado por meio do planejamento, objetivando perce- 
ber o plano colocado em ação, as sensações que iria provocar nas crianças e se elas estavam sendo contempladas nos seus direitos.

Fomos percebendo ainda mais a importância que tem o planejamento, assim como os outros instrumentos pedagógicos (observação, registro, avaliação, reflexão). Consideramos que nem tudo que planejamos vai ao encontro da criança e de seus anseios, mas se a ela for colocada em primeiro lugar, como centro do processo, e se tiver seus direitos vislumbrados ao máximo, aí sim o planejamento vai fazer sentido para todos os envolvidos no processo e a criança se sentirá motivada a entrar na atividade.

\section{Referências}

BIANCA et al. Princípios Básicos de Vygotsky sobre a Aprendizagem e o Desenvolvimento. [20--]. Disponível em: <http://www.angelfire. com/mo/giulli/psico.html>. Acessado em: 27 dez. 2012.

BENJAMIN, Walter. Magia e técnica, arte e política: ensaios sobre literatura história da cultura. São Paulo: Brasiliense, 1994. p. 254. (Obras escolhidas, v. 1).

CACCIOLARI, Neide Aparecida. A importância da contação de histórias para o futuro da leitura literária no século XXI: cibercultura, literatura, escola e novas tecnologias - uma ponte necessária. 2009. Disponível em: <www.faccrei.edu.br/gc/anexos/diartigos39.pdf>. Acesso em: 27 dez. 2012.

CHARLOT, Bernard. O "filho do homem": obrigado a aprender para ser (uma perspectiva antropológica). In: Da relação com o saber: elementos para uma teoria. Porto Alegre: Artmed, 2000. p. 51-58.

DANTAS, Jéferson. Formação docente em serviço e construção curricular nas escolas associadas à Comissão de Educação do Fórum do Maciço do morro da Cruz. Cadernos do Ceom. Chapecó: Unochapecó, 
n. 30, 2009. Disponível em: <https://apps.unochapeco.edu.br/revistas/ index.php/rcc/article/view/467>. Acesso em: 18 dez. 2012.

DUARTE, Cléber. Cultura e educação. [20--]. Disponível em: <http://sociologiamelhormateria.blogspot.com.br/2011/04/cultura-eeducacao.html>. Acesso em: 15 fev. 2013.

FREIRE, Madalena. Planejamento: sonhar na ação de planejar. In: ; DAVINI, J.; CAMARGO, F.; MARTINS, M. C. Avaliação e Planejamento: a prática educativa em questão, instrumentos metodológicos II. São Paulo: Espaço Pedagógico, 1997. p. 54-58. (Série Seminários).

FREIRE, Paulo. Pedagogia do Oprimido. 9. ed. Rio de Janeiro. Paz e Terra, 1981.

HONORATO, Aurélia Regina de Souza. A imaginação e a infância. [20--]. Disponível em: <www.gedest.unesc.net/seilacs/infancia_ aureliahonotato.pdf $>$. Acesso em: 27 dez. 2012.

MELLO, Suely. A apropriação da escrita como um instrumento cultural complexo. In: MENDONÇA, Sueli Guadelupe de Lima; MILLER, Stela (Orgs.). Vigotski e a Escola Atual: fundamentos teóricos e implicações pedagógicas. Araraquara: Junqueira \& Marin, 2006. p. 181-192.

SARMENTO, Manuel Jacinto; PINTO, Manuel. As crianças e a infância: definindo conceitos, delimitando o campo. In:

(Coords.). As Crianças: contextos e identidades. Braga: Universidade do Minho, 1997.

SCHREIBER, Dayana Valéria F. A.; GARCIA, Rosalba Maria C. Trabalho docente e educação especial no Brasil: um estudo no campo da política educacional. Florianópolis, 2012. p. 15. (Seminário).

SILVA, Tomaz Tadeu da. Quem escondeu o currículo oculto. In: _. Documentos de identidade: uma introdução às teorias do currículo. Belo Horizonte: Autêntica, 1999. p. 77-152.

SOUZA, Bruno de et al. Lev Vygotsky, o teórico do ensino como processo social. [20--]. Disponível em: <http://seminariovygotsky. 


\section{Notas}

* Artigo elaborado com base no relatório de estágio "Ler e escrever para voar, viajar, libertar! O diário como meio formativo" da $8^{\mathrm{a}}$ fase do curso de Pedagogia no segundo semestre de 2012; trabalho orientado pela pós-Dra ${ }^{a}$. Maria Isabel Batista Serrão.

** Acadêmicas do curso de Pedagogia da Universidade Federal de Santa Catarina (UFSC). Joice Taise Martins: <joice.taise@hotmail.com>. Larissa Gimenes de Araújo: <lara_araujo88@hotmail.com $>$.

${ }^{1}$ Ver site: <http://seminariovygotsky.blogspot.com.br/p/textos.html >.

${ }^{2}$ Mediante este termo "despertam", faz-se ressalva, pois compreendemos que esta palavra "despertar" induz a entender que o aprender é inato, entretanto a aprendizagem contribui para a formação e desenvolvimento desses processos internos e não os despertam, como se fossem algo adormecido por algum motivo, como se o indivíduo já nascesse com eles.

3 "O termo 'maciço' refere-se ao recorte geomorfológico irregular onde se concentra uma população plural repleta de signos culturais, sociais e geográficos, encravada numa sucessão de comunidades com identidades próprias, resultado de práticas migratórias inter-regionais." (DANTAS, 2009, p. 435). 
JOICE TAISE MARTINS

LARISSA GIMENES DE ARAÚJO 